\title{
Economic Model of Generation Z Behavior
}

\author{
Liliia Matraeva ${ }^{1}$ \\ Ekaterina Vasiutina ${ }^{1}$ \\ Alexey Belyak ${ }^{1}$ \\ Petr Solodukha ${ }^{1}$ \\ Nataliya Bondarchuk ${ }^{2}$ \\ Marina Efimova ${ }^{3}$ \\ ${ }^{1}$ Russian State Social University, Moscow, Russia \\ ${ }^{2}$ Financial University under the Government of the \\ Russian Federation, Moscow, Russia \\ ${ }^{3}$ State University of Management, Moscow, Russia
}

Doi: 10.36941/ajis-2019-0011

\begin{abstract}
The model of an entity that makes decision and acts in accordance with the established rules or contrary to them, participating in creation or changing of rules. All of that is a starting point for the analysis of economic processes and phenomena that are determined by the initiator of economic development - by a person. However, each generation brings its own features to economic behavior model and has its own characteristics. In this paper, the authors highlight the consequences of generation civilizational change within the framework of the digital society formation, determine the features of formation and development of the modern generation from the theoretical point of view of N. Howe and T. Strauss. Based on the data of large-scale sociological studies conducted in 2016 by Sberbank of Russia and the All-Russian Public Opinion Research Center and MAGRAM Market Research with PBN Hill Knowlton Strategies international communications agency, the features of the digital culture influence on the social model of Generation $Z$ behavior and the problems of its formation at the present stage are determined. An emphasis is placed on its specificity and uniqueness. 4 main features of economic model of Generation $Z$ behavior that are developed in Russia are stated and the risks associated with these features are described.
\end{abstract}

Keywords: civilizational change; theory of generations; digital economy; economic behavior; Generation Z

\section{Introduction}

Various motives of the person (entity) activity prompt the formalization of individual trends into a kind of profile, a model of human economic behavior, that is, a unified view of a person acting in a particular system of socio-economic relations. The model of "economic behavior", like any scientific model, includes the main parameters that characterize the individual: the motives of economic activity, its goals, as well as the person cognition used to achieve the stated goals.

The model of principally abstract nature reflects in a generalized form the main parameters inherent in the "human factor" in economic processes. This knowledge allows not only to assess the human role in the economy at various stages of the society development but also to create the 
most optimal directions in economic policy, to predict with a high degree of probability the consequences of economic decisions.

Considering a person as a certain theoretical premise, the model makes it possible to form the long-term development trends for both society as a whole and individual economic processes that affect the main macroeconomic parameters: economic growth, the level of employment and unemployment, the level of saving, etc.

It is feasible to point out two main theoretical approaches to the analysis of economic behavior models: the traditional approach based on the principle of rational decision-making by economic agents (Friedman 1966, Fama 1970, Stigler 1950) and behavioristic approach where the system of the behavioral factors defining the choice of subjects dominates (Kahneman, Tversky, 1979, Statman 1999 Thaler 1999, Clarke, 2008, Barberis, Thaler 2003). It is necessary to tell that such a split is very conditional as subject of the analysis is cross-disciplinary, and the problem of economic behavior research was complemented with a contribution of sociological and psychological theories (Rosenstock, Victor, Strecher, Becker 1988, Xiao, Newman, Prochaska, Leon, Bassett, Johnson 2004, Osteen, Muske, Jones 2007, Deacon,Firebaugh, 1988; Goldsmith, 2000), which dramatically changed the vector of factor analysis by shifting the focus from objective economic factors to subjective, defining internal motivation. The intersection of research areas and complementary effects of interdisciplinary approaches are well disclosed in Nurco, D. N., R. M., Lerner (Nurco, Lerner, 1999), and Xiao, J. J., and J. Wu., (Xiao, Wu 2006).

Evolution of scientific views in acceptance of economic solutions through rational and behavioral approaches is presented in the researches Kuzina O.E. (Kuzina 2004), Jurevikieny, D.; Gausieny, E. (Jurevikieny, Gausieny 2010), Ozmete E., Hira T. (Ozmete, Hira 2011) and Xiao, J. J. (Xiao 2008).

It is interesting that in works of both rational, and behavioristic approaches, the role of social demographic factors in formation of economic behavior model and its implementation was emphasized. However, if originally it was talked only of age clusters as, for example in model of the behavioral theory of life cycle formulated by R. Taler and H.M. Shefrin (Sheffrin, Thaler 1988), then afterwards it resulted in the following: people of one demographic group integrated by unique historical experience which puts civilization shift within alternation of generations rose, and creates premises for change of model of economic behavior.

Therefore, the purpose of this study was to determine, on the basis of an integrated approach, whether the change of generation brings something new to the existing model, whether economic incentives, decision-making algorithms and sustainable behavior reactions are transformed.

From a methodological point of view, such an approach makes sense only when it meets two simple criteria. First, it should explain differences in behavior better than based on other signs. Second, members of one group should exhibit similar behavior than subjects drawn from different groups. Regarding the first criterion, it became apparent that the behavioral life cycle theory model of R. Thaler and H.M. Schefrin shows a deviation from the findings, especially recently, and requires clarification, by introducing new influence factors (Sushko 2017). Regarding the second criterion, the nature and intensity of civilizational shifts should be analyzed. If there are no civilizational shifts in the process of generations change, and the novelty brought by the generation is based only on traditional values (institutions) and behavioral stereotypes, then there will be no paradigm shift of economic development, there will be adaptation, adjustment of the model, but trends remain, and therefore continuity of development, including economic development.

\section{Literature Review}

\subsection{Civilizational change in the digital economy and the theory of generations: the economic aspect}

Civilizational shifts are an integral part of society development, but each has its own characteristics and the transformation power. Often civilizational shifts involve a shift in the social paradigm of generations.

For the first time the term "paradigm" (after the Greek, the "pattern, example, model") was 
introduced into the scientific use by T. Koon. According to his original interpretation, it meant a "certain set of concepts or patterns of thinking including theories, research methods, postulates and standards in accordance with which the subsequent constructions, generalizations and experiments in the field are made" (Kun 2009). Now this concept is used by scientists in two main aspects. In a wide sense, the paradigm represents a general picture of the nature rational arrangement. Strictly speaking, the paradigm is a set of beliefs, values, technical means, etc., that unite the specialists in this scientific community. Speaking about changing the social paradigm of generations within the framework of civilizational changes concept, we use this term in a wide sense implying that the changes at a certain stage of civilization development are gradually accumulating in the processed resources, production technologies, models of people economic behavior, public institutions that lead to change in value orientations and model of social behavior.

The change in the social paradigm of generations is due primarily to the transformation of the values basic system, which usually turns out to be formed at the time of maturity, and in the future not changing a lot. A large number of studies confirm that people's basic values become fixed by the time they become adults, and further change comparatively little (Rokeach 1968, Rokeach 1973, Inglehart 1977, Baker, Dalton, Hildebrandt 1981). Schumann and Scott argue that each generation has a "collective memory" - acquired in youth, it is preserved by its representatives for the lifetime (Schumer, Scott 1989). Although in the process of socialization a young man assimilates cultural traditions, this does not always mean the reproduction of a specific system of values and beliefs in a constant form. They are most likely to adopt values that correspond to their immediate experience during the period of personality formation, and abandon those that do not conform to it (Inglehart 1997). In addition, the belief system and the model of economic and social behavior itself are influenced by the manner and channels of transmission of these values, generally speaking the information transfer technologies that form the personality of the subject. And it is the latter, according to a large number of researchers, that creates the prerequisites for a civilizational shift of a new order that fundamentally changes the economic pattern of behavior (Agarwal, Driscoll, Gabaix, Laibson 2009; Castells 2000).

The transition to the digital economy model that occurred within the previous wave of the postindustrial society evolution was characterized by the fact that in all spheres (and not only in the economy!) the information reproduction system focused primarily on the human mental performance began to develop (Pugach 2011, Andreeva 2017, Castells, Himanen 2002). Consequently, after a steady period of digitalization, significant differences in the value priorities of younger and older age groups must be evident: this is due to the difference in their experience during the period of personality formation (Inglehart, Welzel 2005).

Basic work devoted to the study of the young transformation problems in the conditions of the information society which caused a great scientific response was the cycle of D. Tapskot's works (Tapscott 1999, Tapscott 2008). In these works he first introduces the term "network generation" that is a generation of young people for whom the basic part of life is transferred to a virtual form where the "social landscape" of the individual is particularly formed", "... using digital technologies for this generation is like breathing" (Tapscott 2008, Nosova 2013). In his book, Tepskot gives a rather favorable image of a new generation. In some degree it is associated with the fact that the book itself appeared as a result of an active discussion of its matter at the forum with the respondents (the same youth about whom he writes) (Nosova 2013). Tepskot believes that generation has clear aspirations for self-dependence, independence, the right to privacy and freedom to speak up. According to his opinion, they are being pushed to the active philosophy of consumption by the desire to distract from the problems and fears of real life. It should be noted that Tepskot actively refers in his work to another landmark work - the "Theory of generations" by N. Howe and T. Strauss (Howe 1991). That work has become an essential interdisciplinary scientific research at the intersection of economics, sociology, psychology and pedagogy. Although the book considers the theory of generations beginning from the XVI century, the most famous and discussed topic in the literature becomes the classification relating to the XX-XXI century within the framework of which it is highlighted the (Shamis):

- GI generation (the Generation of Winners)

- Silent Generation 
- Generation of baby boomers or boomers

- Generation X (Unknown Generation)

- Generation $Y$

- Generation Z

Tapskot associates the fact of the "network generation" formation with the generation $Y$ and calls it the "Millennium generation" as its representatives graduate from school in the new millennium.

Table 1 shows the author's position of the features of models of the XX-XXI centuries generations economic behavior on the example of Russia systematized on the basis of the sources study. The events formed the values of these generations and their features were compiled by the authors according to works (Howe 1991, Shamis, Kulakova 2018, Vorontsova 2016).

Table 1. The main features of the XX-XXI centuries generations (the Russian aspect)

\begin{tabular}{|c|c|c|c|c|}
\hline $\begin{array}{l}\text { Name of the } \\
\text { generation }\end{array}$ & $\begin{array}{c}\text { Period of } \\
\text { birth }\end{array}$ & $\begin{array}{c}\text { The events that formed } \\
\text { the values }\end{array}$ & Features & $\begin{array}{c}\text { The features of economic } \\
\text { behavior model }\end{array}$ \\
\hline $\begin{array}{l}\text { Generation GI } \\
\text { (the Generation } \\
\text { of Winners) }\end{array}$ & $1900-1922$ & $\begin{array}{c}\text { revolutionary events of } \\
1905 \text { and } 1917\end{array}$ & $\begin{array}{l}\text { diligence, responsibility, } \\
\text { almost religious belief in a } \\
\text { bright future, commitment to } \\
\text { ideology, family, dominance } \\
\text { and categorical judgments }\end{array}$ & $\begin{array}{l}\text { survival-oriented consumption and } \\
\text { minimum level of needs (focus on } \\
\text { primary needs) }\end{array}$ \\
\hline Silent Generation & 1923-1942 & $\begin{array}{l}\text { repression, World War II, } \\
\text { the restoration of a } \\
\text { destroyed country }\end{array}$ & $\begin{array}{l}\text { loyalty, observance of rules, } \\
\text { laws, respect for position } \\
\text { and status, honor, patience }\end{array}$ & $\begin{array}{l}\text { a high degree of saving of tangible } \\
\text { and monetary assets due to } \\
\text { deferred consumption, minimalism } \\
\text { and conservatism in consumption }\end{array}$ \\
\hline $\begin{array}{c}\text { Generation of } \\
\text { baby boomers or } \\
\text { boomers }\end{array}$ & 1943-1962 & $\begin{array}{l}\text { the Soviet "thaw", the } \\
\text { USSR - is the world } \\
\text { superpower, the "cold war", } \\
\text { the unified standards of } \\
\text { education in schools and } \\
\text { the guarantee of medical } \\
\text { care, the generation with } \\
\text { the psychology of the } \\
\text { winners }\end{array}$ & $\begin{array}{l}\text { optimism, initiative, team } \\
\text { spirit, the cult of youth, } \\
\text { confidence in the future }\end{array}$ & $\begin{array}{l}\text { interest in personal growth and } \\
\text { reward, at the same time, a rich } \\
\text { orientation towards collectivism, } \\
\text { consumption carries a status } \\
\text { connotation and is able to confirm } \\
\text { the merits. They are ready to try } \\
\text { something new but at the same } \\
\text { time they are reasonably } \\
\text { conservative }\end{array}$ \\
\hline
\end{tabular}

\begin{tabular}{cc}
\hline $\begin{array}{c}\text { Generation X } \\
\text { (Unknown }\end{array}$ & $1963-1982$ the continuation of the Co \\
Weneration) & War, Perestroika, AIDS, \\
drugs, the war in \\
Afghanistan
\end{tabular}

Generation Y 1983-2002 the disintegration of the

("Network

generation", the

generation of

"Millennium") USSR, terrorist attacks, of epidemics, economic readiness for change, choice, technical literacy, individualism, the desire to learn throughout life, the informality of views, the search for emotions, pragmatism, self-reliance civic duty, morality, responsibility, but at the military conflicts, outbreaks crises, the development of digital technologies, the era immediate remuneration for of status items same time naivety and the ability to obey. The immediate reward is labor the concept of forced (organic) rationality dominates: they do not seek to maximize their welfare but consumer behavior is corrected by established social institutions (formalized and unformalized rules and standards)

information and knowledge become an industrial resource. Scientific developments become the main driving force of the economy. The most valuable qualities are the level of education, professionalism, trainability and creativity of the employee.

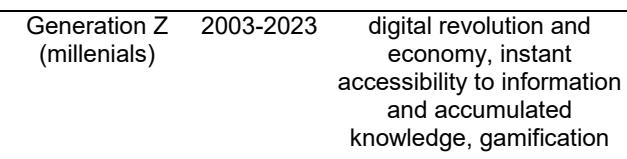

possession of information generates self-confidence, bordering on selfconfidence, egocentrism, virtual collectivism, in combination with personal individualism, quickly

change of one activity to

another values are clearly intangible, consumption for pleasure, reduced risk appetite (business initiative), lack of motivation for long-term saving. The main asset is the ability to work in a real team.

Source: Compiled by the authors on works (Howe 1991, Shamis, Kulakova 2018, Vorontsova 2016). 
The intergenerational change hypothesis, introduced into scientific circulation long before data for many countries were collected, allowed for the prediction of the presence of both persistent differences between cohorts and period specificity effects, which were later observed in reality (Hofstede 2011). The thesis of changing the economic pattern of behavior in connection with the change of generations also predicts that in the long term there will be changes in all countries where digital technologies will take a dominant position (Dudin, Lyasnikov, Dobrova, Vysokaja, Katulsky 2014).The study of the civilizational change problems influencing the economic model of human behavior within the framework of the digital economy development is still at the stage of conception but the attention of scientists is still not very focused on this topic. This is due to two main reasons:

Firstly, the paradigm change, in principle, does not in itself occur too clearly, as, for example, the economic crisis or other events that clearly attract the attention of economist scholars.

And secondly, right now we observe the formation of generation $Z$ which is just the beginning of its active labor activity, and therefore we can't fully appreciate the consequences of the effects of these transformations on the type of socioeconomic behavior model of the participant in economic activity. That is why in today's scientific literature there is an ambiguous discussion about the generations $Y$ and $Z$ called "Born Digital" by the scientists. Among such works the special attention should be paid to the works of Montgomery K.C., Palfrey J., Gasser U. (Montgomery 2007, Palfrey 2008) who systematize not only the positive but also the negative consequences of these transformations.

\section{Materials and Methods}

To study this phenomenon in Russia couple of standard social studies were undertaken: WCIOM \& Sberbank study in 2016 (Selfie generation); a "Young \& Younger" study conducted by MAGRAM Market Research in conjunction with the international communications agency PBN Hill Knowlton Strategies in 2017 (8 differences). As age of Generation Z representatives on labor market is now between 14 and 18 such studies are not so common but likely to happen in further years.

As studies were held not on regional level but on country level number of respondents were 1600 - standard value for WCIOM studies (WCIOM) and 1500 - MAGRAM Market Research. The last one was conducted in the format of an online survey in 15 cities milliners of Russia among 1500 young people in April-May 2017. Generation $Y$ was presented by participants aged 18-35 years, and generation Z - from 14-17 years. And only part of it is dedicated to Generation Z itself so the decision was to continue with WCIOM study.

The All-Russian Center for Public Opinion Studies (WCIOM) is the oldest Russian research institute in the field of social, political and marketing surveys and has been working for 30 years since 1987. The company's activities have been aimed at obtaining, analyzing and disseminating reliable information on the state and dynamics of social development, public opinion, mass consciousness and behavior characteristic of various social groups of the population and territorial communities. Since 1990, WCIOM has conducted about 1,000 regular All-Russian representative surveys ("omnibuses"). Until 2005, such surveys took place monthly, then weekly, and since January 2017 - daily. WCIOM today is more than 100 full-time employees, including candidates and doctors of science. The geography of WCIOM research covers Russia, North and South America, the EU, the Middle East, Southeast Asia, and the post-Soviet space.

Typical Study Parameters:

Description of WCIOM test parameters is based on ESOMAR/WAPOR Manual:

- Name of the organization that is conducting the survey

- Description of the total population

- Total sample size/number of focus groups conducted, expert interviews

- Geography of the study (Russia as a whole - 1600 respondents; each of 85 regions 50000 respondents)

- Sampling Method/Respondent Selection Principle

- Sample Error Estimate if Applicable to Study Design 
- Survey Method

- Description of the procedure for weighing data, if any

- The document containing research information (survey data) also indicates: the exact wording of the questions asked; the answers "I find difficult," refusal to answer. "

Quality control of the obtained information

Quality control of the obtained information is implemented step by step:

- Before start of the project detailed instructing of interviewers and piloting of the questionnaire is carried out;

- Control of interviewers by supervisors in poll points is exercised.

- Visual check of the completed questionnaires is made.

- Operational telephone survey of respondents for the purpose of check of the fact of holding an interview and control of reliability of the received answers on social and demographic and some key parameters of poll $(20 \%)$ is carried out.

- After data entry statistical monitoring of errors of input is provided.

- After association of data arrays error analysis of input at the central office is made.

- Within 3 days from the moment of obtaining the general database control telephone survey is carried out $(20 \%$ of the general selection with observance of regional proportions).

After field data is collected processing is made using the following methods: descriptive statistical analysis of data, multidimensional data analysis (component, cluster analysis, correspondents-analysis, multidimensional scaling, multiple regression), regression correlation analysis, statistical testing of hypotheses, modeling, tipologization, qualitative analysis of content of focus groups and deep interviews.

Authors used a method of content analysis intended to analyze the semantic content of textual arrays on the subject of research, as well as tools for inductive and deductive analysis which made it possible to combine separate conclusions on this problem and formulate the author's vision of the problem. When constructing and describing models, the authors adhered to the principles of an integrated approach which made it possible to establish the most significant relationships and trends in phenomena and processes and to formalize the most significant effects.

\section{Discussion}

1. The study completes the generations theory of N. Howe and T. Strauss due to a fuller explanation of the Generation Z (born in 2003-2023), its features and specifics related to the model of economic behavior which the authors systemize on the basis of large-scale sociological studies results conducted in 2016 by Sberbank of Russia and the All-Russian Public Opinion Research Center.

2. The research is interdisciplinary: for the first time in such a study, the focus is shifted to the particularities of the developing generation economic model. It is concluded about its exceptionalism which can result in a revision of classical economic models based on behaviorism: the theory of demand, motivation, saving and consumption.

3. The authors using the example of a specific country (Russia) identify possible risks that are formed within the framework of the new model of the Generation $Z$ economic behavior.

4. Alternative study made by MAGRAM Market Research targeted two generations $Y$ and $Z$ so Sbarbank's study is more relevant and describes better Generation Z representatives.

\section{Results}

\subsection{The influence of digital culture on the social model of behavior: the problems of generation $Z$} at the present stage

Perhaps, for the first time in history, the children are so different from their parents. Our basic social institutions are changing under their pressure and many of them have been formed for millennia 
such as the family, the church, and many others. The new generation is radically different from the previous ones which means that we can expect some kind of changes in long-term trends, on which the government's current economic policy is still built.

As noted above, the Generation $Z$ formation caused primarily by the digital revolution triggered not only the change of value orientations but also gave rise to a whole set of problems which can be described with confidence as a civilizational change associated with the transfer of a significant part of the public and social life of modern adolescents in virtual space.

Further analysis of the article will be built on the study of Sberbank which collected the basic facts about the $Z$ generation reflecting a number of features of the "psychological portrait" and the data of the All-Russian Public Opinion Research Center (VCIOM) on modern youth. The results of these studies were published in December 2016 (30 facts, Selfie generation, Shatto 2017). As follows from the release of the credit institution, this is the largest in its history qualitative research of this segment of potential customers. The need for research is due to the presence of a temporary lag in Russia to intensify the economic activity of generation $Z$ and to compare the emerging trends in the formation of the economic model with the global ones. Our attention was attracted by the following trends which clearly provoke significant transformational changes in the human "economic model", and, therefore, require response at the level of economic policy planning:

1. Fast shifting was compensated by the lack of concentration and depth of questions elaboration.

They tend to perceive only a brief, visual information that is consumed by small, "snack" portions while icons, smiles and pictures often replace the text. The attention of children of $Z$ generation is difficult to retain on anything because the Internet allows them to be simultaneously in several browsers: music, video, correspondence, forum. In the multitasking mode, they feel very confident but focusing on one task and bringing it to the end requires considerable effort from them.

2. Lack of long-term trends, minimal planning horizon.

Social networks form a sense of flow where everything changes every second, so the $Z$ generation is characterized by a minimal planning horizon.

3. Behavioral motivational model has changed.

There is a characteristic rejection of a gradual movement towards success, it is occurred a change in value orientation related to the lack of interest in real life and world. The value system shifts to a virtual environment, the concept "value" by itself blurs, loses its material form that facilitates the conversion of this concept into an abstract form.

4. Hedonism set which extends to work activity.

According to the youth opinion the happiness is actually a success itself. It is measured by the variety of life and pleasure rather than by wealth and status. Work should be fun and, of course, bring in income but do not take a lot of time: the young people are not ready to work very hard. The words "career" and "prestigious work" are not available in the answers. The main expectations from the future are comfort and tranquility.

5. The habit of separating oneself from the state, from the family develops, autonomization of the person takes place, and as a result - the bias towards individualism.

The search for one's way is the basic attitude and value of the $Z$ generation. The ideology based on the process of joint activity and the desire to be useful to other people, nature and the world as a whole is abstract. The modern generation does not have "recognition of the Motherland image", and, consequently, its understanding. Awareness and acceptance of the idea of patriotism in this connection is difficult, and the system of motivation built on real commitment to anything becomes ineffective. Representatives of generation $Z$ state that they do not have idols ( $57 \%$ of them answered "no" and $16 \%$ of them found it difficult to answer) (Selfie generation), and the persons whom they really want to imitate are more likely relatives and historical characters.

6. Loss of the orientational norms of coexistence in a single territory associated with the vague concept in a modern virtual environment.

This causes a slow formation of norms and rules of coexistence in one territory, responsibility for it and the need to reach agreements for joint existence, generates 
difficulties in working with a permanent team "in real life."

7. Fear of "ordinary" life without spontaneity, intense feelings and vivid impressions.

8. The passive attitude of children towards their own health remain unchanged.

Modern children have a sedentary lifestyle. Movement is changed by many hours-long sitting glued to the TV or computer and it suits them.

\subsection{Transformation features of economic model of the Generation Z behavior}

System analysis of such elements as information processing, self-perception, system of values, frustrations, fears and expectations from the Generation Z gives ground to speak about the problems formation in the future. The solution of those problems is simply impossible in the current institutional environment of economic policy.

Firstly, we understand that the pursuit of values that are clearly intangible becomes actual: finally, the impressions, travels, and entertainments become more valuable acquisitions than the well-fixed philistine life overburdened with the real estate, assets, property and responsibility. The lifestyle of parents and the older generation frightens according to the perception of the Generation $Z$, and, consequently, that generation rejects the traditional model of "economic behavior" where the goal is a profitable prestigious job, family and material wealth.

Secondly, it can be expected that the pursuit of comfort and tranquility as the main target motivational goal reduces the extreme risk appetite - the main factor of business activity and the formation of a business initiative.

Thirdly, lack of patience and concentration, collateral perception of information, the desire to obtain a result without a period of entry and expectation speak for orientation on projects with a short period of return on investment and effort. These features will also affect the labor market as rejection of the model of gradual movement towards success will lead to high turnover at the workplaces.

Fourthly, a short planning horizon will invariably affect the process of saving. Even now, the generation has no ambition for saving that will result in draining away of one of the key sources for the long money formation within a market economy. A low degree of perception and vision of longterm trends makes it impossible to form such trends psychologically and intellectually both at personal and societal level. It should be noted that the traditional models of economic development describes the rate of saving as a guarantee of economic balanced- growth path. E. Phelps states in his rule that a balanced growth of the economy is that each generation saves for the future generations the same fraction of national income left by the previous generation (Edmund 1966, Evain 2012). The lack of motivation for saving violates this condition that can lead to the contracted reproduction within the long-term period.

Additional risks are also created for the pension system. Otto von Bismarck's classical system of pension provision is an unfunded relationship in time between generations. Funding of assets paid to the pension funds from the current incomes of the economically active population founds the current provision of pensioners. The system provides that when the recent pensioners reach retirement age, the people who entered the labor market and joined the ranks of the economically active population will take care of them. However, it turns out that the lower limit of replenishment of these series is blurred. The new generation prefers to look for themselves up to 30-35 years, appreciates the free schedule, independence that leads to the rejection of permanent employment, career growth, official wages and the preference for freelance and current consumption. The age of survival for modern youth is also not so relevant as the concern for material well-being, a healthy lifestyle, and so on. The system ceases to work and the problem is not in the absence of competent state policy, demographic problems, etc., but the problem is in economic psychological motivations that impede the effective functioning of the pension system within the long-term period. The contradiction between the principles of the pension system functioning and the behavioral model of the Generation $Z$ will only increase. A simultaneous deterioration of the financial solvency of the distribution pension system and a reduction in the need for it in a society where the Generation $Z$ joins the ranks of the economically active population determine the futility of modern attempts to increase the retirement age and keep the current model in functional condition. 
The problem of long money that is always lacking in the economic system for its normal functioning is supplemented by medium-term problems where the culprits again become fashion and trends brought to the economic reality by centennials. This is a powerful trend - crypto currency formed in the monetary system. Young and daring people became conductors and active adaptors of a new financial instrument. The lists of millionaires holding their assets in crypto-currencies contain people mostly belonging to the Generation Z. While for most states the inclusion of circulation of crypto-currency into the institutional state contour is only in the phase of formation. There are no regulatory mechanisms for taxation from such operations, there is no well-established understanding and state regulation of this sphere in principle. In turn, the supra-national character of the crypto-currency leads to the emergence of an area where there are no formal institutions and the rules of the game are formed before long. What does it mean for a specific country and for a specific state? Preference for traditional financial instruments and monetary assets - cryptocurrencies, in fact, derives from the state control and accounting even those funds that the Generation $Z$ earns. Thus, the material basis formed by the youth for social organization, the reproduction of the economic system as a whole, the existence of the state and economic growth is reduced more even taking into account the motivational preferences of the youth.

First of all, the most vividly described changes will be manifested in the labor market since now the Generation Z who was born after 2002 appears on the modern labor market. And as late as in 2017 - 2018 a whole cycle of articles devoted to these changes has appeared in Russia (Yakutin 2018, Pugach 2011, Andreeva 2017, Kupriyanovsky 2017). The systematization of the authors views of these works on the ongoing changes in the labor market in Russia made it possible to identify those aspects that, in our opinion, require changes in the classical treatment and tools in the first place:

1. The transfer of the demand emphasis for intellectual labor except but in certain industries.

2. Transformation of the system of value orientation and motivation of employees.

3. Increasing the value of information as a necessary resource for the formation of competitive human capital.

4. Substantial expansion of the information field necessary for the creation and maintenance of human capital which has an effective demand in the market.

5. Transformation of the concept of "economic value", its transfer to the non-material sphere.

6. Change in the sphere of knowledge and skills transfer.

7. Increasing importance of soft skills in the labor market - the social adaptation and teamwork skills (Andreeva 2017).

\section{Conclusions}

Sberbank collected the main facts about Generation Z. The largest Russian bank published a report dedicated to "centenials" (name given by Sbarbank to born after 2002), where it gave its recommendations on working with young people.

1. Advertising and information for young people should be shifted to the Internet.

2. Show rather than tell to hold the attention of centenials.

3. The only way to interact with them is through persuasion.

4. Generation $Z$ does not believe very much in a bright and beautiful future.

According to experts, Generation Z will seek alternative employment schemes, so it makes sense to think about special products for freelancers and remote workers.

Thus, the peculiarity of the Generation $Z$ is, in its own way, a fundamentally different consumer and target behavioral model in the labor market. The behavioral model in the labor market is associated with the shifting of priorities towards the "social comfort": the desire for comfort and tranquility, the lack of motivation for saving, the desire for social recognition of labor results, the low level of business initiative, the lack of long planning horizons, the low level of "personal" socialization. The consumption-oriented model is based on the concept of consumption not for the sake of satisfying the needs but for the sake of pleasure. The very process of buying delivers it. At the same time consumption itself has shifted towards the Internet from the point of view of the place of the transaction conclusion. In addition, the Generation $Z$ is the largest consumer of information 
services and gadgets.

The formulation of questions related to the transformation of the model of human economic behavior within the framework of new social formations is now extremely important as they reflect global trends rather than random deviations that can be corrected with the help of known tools. It is proved that the forming Generation $Z$ has a significant level of individuality from the point of view of economic behavior and is capable of bringing significant risks to the current model of Russia's state economic development up to the changes in established traditional models of socio-economic relations based on behaviorism: demand theory, motivation, saving, and consumption. It should be especially noted that the problem of regulating such risks is complicated by the fact that at present the state is dealing with a system that is itself in a phase of formation and undergoing changes, therefore, it is quite difficult to adapt to it taking into account the time lag for making decisions and introducing them at the state level. However, if we forget about these changes and do not take them into account when improving the models of socio-economic processes, then we can face completely ineffective decisions as they transform the laws of human involvement into the existing economic system.

\section{References}

30 facts about modern youth: the study of Sberbank and Validata (2017) Yangspace. №11.

8 Generation Z \& Generation Y Differences (2017) "Young \& Younger" study conducted by MAGRAM Market Research in conjunction with the international communications agency PBN Hill Knowlton Strategies. Available at https://www.retail.ru/articles/8-otlichiy-pokoleniya-z-ot-pokoleniya-y/

Agarwal, S., Driscoll, J. C., Gabaix, X., \& Laibson, D. (2009). The age of reason: Financial decisions over the life cycle and implications for regulation// Brookings Papers on Economic Activity, 2. - P. 51-117.

Andreeva L., Dzhemaev O. (2017) The influence of the digital economy on the formation of new trends in the Russian labor market. State and municipal management. Scientific notes of SKAGS №3. P. 25-32.

Baker K.L., Dalton R.J., Hildebrandt K. (1981) Germany Transformed. Cambridge, MA: Harvard University Press.

Barberis, N. C., \& Thaler, R. H. (2003). A Survey of Behavioral Finance. In Handbook of the Economics of Finance (pp. 1053-1128). North Holland: Elsevier Science.

Castells M. (2000) The Information Age: Economy, Society and Culture. Vol.1 Cambridge, MA, Oxford, UK: Blackwell.

Castells M. , Himanen P. (2002) The Information Society and the Welfare State: The Finnish Model. Oxford University Press. Oxford.

Clarke, B. (2008) Models of Behavior Change. http://www.srdc.msstate.edu.

Deacon, R.E., and F.M., Firebaugh (1988) Family Resource Management: Principles and Applications. Boston, MA: Allyn and Bacon.

Dudin M.N., Lyasnikov N.V., Dobrova K.V., Vysokaaja H.V., Katulsky E.D. (2014) Peculiarities of consumer behaver management of young people in e metropolis - world experience// Asian Social Science. Vol.10, № 20. P. 38-46.

Edmund S. (1966) Phelps Golden Rules of Economic Growth: Studies of Efficient and Optimal Investment. W.W. Norton and Company, ins. First edition, p. 189.

Evain, C., Carolan, S., Magnin, M. (2012) Preparing for generation Z: The hippocampus experiment at the Ecole Centrale de Nantes. ASME 2012 11th Biennial Conference on Engineering Systems Design and Analysis, ESDA 2012 Volume 4, P.p. 291-299. ASME 2012 11th Biennial Conference on Engineering Systems Design and Analysis, ESDA 2012; Nantes; France; 2 July 2012 to 4 July 2012

Fama, E. (1970). Efficient capital markets: A review of theory and empirical work. The Journal of Finance, 25(2), 383-417. doi:10.2307/2325486

Friedman, M. (1966). The methodology of positive economics, in Essays in Positive Economics. Chicago: University of Chicago, 3-43.

Hofstede G. (2011) Dimensionalizing Cultures: The Hofstede Model in Context/Online readings in Psychology and Culture. 2(1). available at http:/dx.doi.org/10/9707/2307-0919.1014.

Howe N., Strauss W. (1991) Generations: The History of America's Future, 1584 to 2069. N.Y. William Morrow \& Company, $554 \mathrm{p}$

Goldsmith, M. (2000) Coaching for Behavioral Change. In Coaching for Leadership, edited by Marshall Goldsmith, Laurence Lyons, and Allyssa Freas. San Francisco: Jossey Bass/Pfeiffer.

Inglehart R. (1977) The Silent Revolution. Princeton: Princeton University Press. 
Inglehart R. (1997) Modernization and Postmodernization: Cultural, Economic and Political Change in 43 Societies. Princeton: Princeton University Press.

Inglehart R., Welzel C., (2005) Modernization, Cultural Change, and Democracy The Human Development Sequence. Cambridge University Press. New York. P.405

Jurevičienè, D.; Gausienè, E. (2010) Peculiarities of individuals' financial behaviour, Business: Theory and Practice 11(3): 222-237. http://dx.doi.org/10.3846/btp.2010.25

Kahneman, D.; Tversky, A. (1979) Prospect theory: an analysis of decision under risk, Econometrica: 263-292. http://dx.doi.org/10.2307/1914185

Kulakova A. (2018) Generation Z: The Theoretical Aspect. Issues of Territorial Development. Issue. 2 (42). pp. $1-10$.

(Kun 2009) Kun T. (2009) Structure of Scientific Revolutions. Moscow. - 310 with. - ISBN 978-5-17-059190-9.

Kupriyanovsky V., Sukhomlin V., Dobrynin A. and others (2017) Skills in the digital economy and the challenges of the education system. International Journal of Open Information Technologies. Issue. 5 №1. Available at

https://cyberleninka.ru/article/v/navyki-v-tsifrovoy-ekonomike-i-vyzovy-sistemy-obrazovaniya

Kuzina O.E. [Economic-psychological modeling of financial behavior of the population]. Psikhologiya. Zhurnal Vysshei shkoly ekonomiki = Psychology. Journal of Higher School of Economics, 2004, vol. 1, no. 3, pp. 83-105. (In Russ.)

Montgomery K. (2007) Generation Digital: Politics, Commerce, and Childhood in the Age of the Internet. The MIT Press. 368 p.

Nosova S., Kuzheleva-Sagan I. (2013) Young people in the network information and communication society: foreign approaches to the study of the problem. Siberian Psychological Journal. №9. p.85-96.

Nurco, D. N., R. M.,Lerner, (1999) A Complementary Perspective to Primary Socialization Theory. Substance Use and Misuse, 34(7):993-1003.

Osteen, S., G. Muske and J., Jones (2007) Financial Management Education: Its Role in Changing Behavior. Journal of Extension, 45(3).

Ozmete E., Hira T. (2011) Conceptual Analysis of Behavioral Theories/Models: Application to Financial Behavior. European Journal of Social Sciences - Volume 18, Number 3 P. 386-404.

Palfrey J., Gasser U. (2008) Born Digital. Understanding the first generation of digital natives. N.Y. 335p.

Pugach V. (2011) Innovative economy, civilizational gap and the system of education. Economics of education. №4. P.103-110.

Rokeach M. (1968) Beliefs, Attitudes and Values. San Francisco:Jossey-Bass.

Rokeach M. (1973) The Nature of Human Values.N.Y.:Free Press.

Selfie generation: five myths about modern youth: a study by the All-Russian Public Opinion Research Center (VTsIOM). Press release 3265. 12/13/2016. https://infographics.wciom.ru/theme-archive/society/religionlifestyle/moral-relations/article/pokolenie-selfie-pjat-mifov-o-sovremennoi-molodezhi.html

Rosenstock, I., M. Victor, J. Strecher, and M. H., Becker (1988) Social Learning Theory and the Health Belief Model." Health Education Quarterly, 15: 175-183.

Shamis E., Antipov A. The theory of generations. Psychology and business available at https://psycho.ru/library/2581

Shatto, B., Erwin, K. (2017) Teaching Millennials and Generation Z: Bridging the Generational Divide. Creative nursing. Volume 23, Issue 1, 1. P. 24-28

Sheffrin H.M., Thaler R.H. (1988) The Behavioral Life-Cycle Hypothesis // Economic Inquiry. № 26. P. 609-643.

Shuman H., Scott J. (1989) Generations and Collective Memories // American Sociological Review.Vol.54. P. 359-381.

Statman, M. (1999). Behavioral Finance: Past Battles and Future Engagements. Financial Analysts Journal, 55(6), 18-27. doi:10.2469/faj. v55.n6.2311

Stigler G. (1950). The development of utility theory // J. of Polit. Economy. V. 58. P. 373-396.

Ekaterina Yu. Sushko (2017) Financial Behavior of the Population and its Determinations. / Finance and Credit, 2017, vol. 23, iss. 12, pp. 670-682.

Tapscott D. (1999) Growing Up Digital: The rise of the net generation. McGraw-Hill Companies, 338p.

Tapscott D. (2008) Growing Up Digital: How the net generation is changing your world, McGrow-Hill, $384 \mathrm{p}$.

Thaler, R. (1999). Mental accounting matters. Journal of Behavioral Decision Making, 12(3), 183-206. doi:10.1002/ (SICl)1099-0771(199909)12:3<183::AIDBDM318>3.0.CO;2-F

Application of the Transtheoretical Model of Change (TTM).Social Science Research Network. http://www.papers.ssrn.com

Vorontsova Y. (2016) Theoretical basis of the theory of generations. Uchenye zapiski Orel State University. Series: Humanities and Social Sciences. No. 3 (72). P. 268-273.

Xiao, J. J. (2008). Applying behavior theories to financial behavior. In J. J. Xiao (ed.). Handbook of consumer finance research (pp. 69-81). New York: Springer. 
Xiao, J.J., B. M. Newman, J.M. Prochaska, B.Leon, R. L. Bassett, and J.L. Johnson (2004) Applying the Transtheoretical Model of Change to Consumer Debt Behavior Financial Counseling and Planning, 15(2): 89-100.

Xiao, J. J.,and J. Wu., (2006) Encouraging Behavior Change in Credit Counseling: An (Yakutin 2018) Yakutin Y. Civilizational shift requires active social policy of the state. Economics and Life. №01 (9717) 2018 available at https://www.eg-online.ru/article/363669/

Official site of All-Russian Public Opinion Research Center https://wciom.ru/about/aboutus/ 